\title{
European Respiratory Society guidelines on long-term home non-invasive ventilation for management of COPD
}

\author{
Begum Ergan (10 ${ }^{1,23}$, Simon Oczkowski ${ }^{2,3,23}$, Bram Rochwerg ${ }^{2,3}$, Annalisa Carlucci ${ }^{4}$, \\ Michelle Chatwin ${ }^{5}$, Enrico Clini ${ }^{6}{ }^{6}$, Mark Elliott ${ }^{7}$, Jesus Gonzalez-Bermejo ${ }^{8,9}$, \\ Nicholas Hart $\mathbb{1}^{10,11}$, Manel Lujan ${ }^{12}$, Jacek Nasilowski ${ }^{13}$, Stefano Nava ${ }^{14}$, \\ Jean Louis Pepin ${ }^{15}$, Lara Pisani ${ }^{14}$, Jan Hendrik Storre ${ }^{16,17}$, Peter Wijkstra ${ }^{18}$, \\ Thomy Tonia ${ }^{19}$, Jeanette Boyd ${ }^{20}$, Raffaele Scala ${ }^{21}$ and Wolfram Windisch ${ }^{22}$
}

@ERSpublications

Managing hypercapnia may be an important intervention for improving outcome of COPD patients with chronic respiratory failure. Long-term home NIV may improve health outcomes by targeting a reduction in $\mathrm{CO}_{2}$ in those with hypercapnic respiratory failure. http://bit.ly/2NlA3eG

Cite this article as: Ergan B, Oczkowski S, Rochwerg B, et al. European Respiratory Society guidelines on long-term home non-invasive ventilation for management of COPD. Eur Respir J 2019; 54: 1901003 [https://doi.org/10.1183/13993003.01003-2019].

\begin{abstract}
Background: While the role of acute non-invasive ventilation (NIV) has been shown to improve outcome in acute life-threatening hypercapnic respiratory failure in COPD, the evidence of clinical efficacy of longterm home NIV (LTH-NIV) for management of COPD is less. This document provides evidence-based recommendations for the clinical application of LTH-NIV in chronic hypercapnic COPD patients.

Materials and methods: The European Respiratory Society task force committee was composed of clinicians, methodologists and experts in the field of LTH-NIV. The committee developed recommendations based on the GRADE (Grading, Recommendation, Assessment, Development and Evaluation) methodology. The GRADE Evidence to Decision framework was used to formulate recommendations. A number of topics were addressed under a narrative format which provides a useful context for clinicians and patients.

Results: The task force committee delivered conditional recommendations for four actionable PICO (target population-intervention-comparator-outcome) questions, 1) suggesting for the use of LTH-NIV in stable hypercapnic COPD; 2) suggesting for the use of LTH-NIV in COPD patients following a COPD exacerbation requiring acute NIV 3) suggesting for the use of NIV settings targeting a reduction in carbon dioxide and 4) suggesting for using fixed pressure support as first choice ventilator mode.

Conclusions: Managing hypercapnia may be an important intervention for improving the health outcome of COPD patients with chronic respiratory failure. The task force conditionally supports the application of LTH-NIV to improve health outcome by targeting a reduction in carbon dioxide in COPD patients with persistent hypercapnic respiratory failure. These recommendations should be applied in clinical practice by practitioners that routinely care for chronic hypercapnic COPD patients.
\end{abstract}

This document was endorsed by the ERS Executive Committee on 14 August 2019.

The guidelines published by the European Respiratory Society (ERS) incorporate data obtained from a comprehensive and systematic literature review of the most recent studies available at the time. Health professionals are encouraged to take the guidelines into account in their clinical practice. However, the recommendations issued by this guideline may not be appropriate for use in all situations. It is the individual responsibility of health professionals to consult other sources of relevant information, to make appropriate and accurate decisions in consideration of each patient's health condition and in consultation with that patient and the patient's caregiver where appropriate and/or necessary, and to verify rules and regulations applicable to drugs and devices at the time of prescription.

This article has supplementary material available from erj.ersjournals.com

Received: 19 May 2019 | Accepted after revision: 13 July 2019

Copyright CERS 2019 


\section{Introduction}

Non-invasive ventilation (NIV) is increasingly being used as a long-term treatment in patients with hypercapnic chronic respiratory failure (CRF) due to various conditions [1,2]. While the role of acute NIV has been shown to improve outcome in acute life-threatening hypercapnic respiratory failure due to COPD exacerbations, the evidence of clinical efficacy of long-term home NIV (LTH-NIV) for management of COPD with hypercapnic CRF is less [3]. Thus, there is an ongoing discussion on whether LTH-NIV should be used in COPD patients or not [4]. For this reason, the European Respiratory Society (ERS) created a task force to develop guidelines aimed at providing evidence-based recommendations on the application of LTH-NIV in CRF for patients with hypercapnic COPD.

\section{Materials and methods}

Task force panel composition

The task force panel consisted of 15 clinical experts in the field of NIV and one clinical practice physiotherapist from ERS Assembly 2 (Respiratory Intensive Care), one clinician representing ERS Assembly 4 (Sleep and Breathing Disorders; and Clinical Physiology), one ERS methodologist (T. Tonia) and two clinician-methodologists (B. Rochwerg and S. Oczkowski) with experience in evidence synthesis and guideline development using GRADE (Grading of Recommendations, Assessment, Development, and Evaluation) methodology. During evidence to decision process, a representative (J. Boyd) from the European Lung Foundation provided COPD patients' perspective from the findings of their home mechanical ventilation survey [5].

\section{Conflict of interest policy}

The task force panel members signed a confidentiality agreement and disclosed all potential financial conflicts of interest in accordance with ERS policy.

\section{Question generation}

An initial list of PICO (target population-intervention-comparator-outcome) questions was developed by the task force chairs (R. Scala and W. Windisch), which was discussed and prioritised in detail by task force members considering the clinical importance, availability of evidence, and patient perspectives. PICOs were then finalised at the September 2017 task force meeting at the ERS conference in Milan. The task force selected six questions for the guideline to address, four PICO questions (table 1), and two descriptive questions to be addressed in a narrative format, which the task force believed would provide useful context for clinicians and patients.

Affiliations: ${ }^{1}$ Dept of Pulmonary and Critical Care, Dokuz Eylul University School of Medicine, Izmir, Turkey. ${ }^{2}$ Dept of Medicine, Division of Critical Care, McMaster University, Hamilton, ON, Canada. ${ }^{3}$ Dept of Health Research Methods, Evidence, and Impact, McMaster University, Hamilton, ON, Canada. ${ }^{4}$ Dept of Pulmonary Rehabilitation, IRCCS-Istituti Clinici Scientifici, Pavia, Italy. ${ }^{5}$ Clinical and Academic Dept of Sleep and Breathing, Royal Brompton Hospital, Royal Brompton and Harefield NHS Foundation Trust, London, UK. ${ }^{6}$ Dept of Medical and Surgical Sciences, University of Modena and Reggio Emilia and University Hospital of Modena, Modena, Italy. ${ }^{7}$ Dept of Respiratory Medicine, St James's University Hospital, Leeds, UK. ${ }^{8}$ Sorbonne Université, INSERM, UMRS1158 Neurophysiologie Respiratoire Expérimentale et Clinique, Paris, France. ${ }^{9} \mathrm{AP}$ HP, Groupe Hospitalier Pitié-Salpêtrière Charles Foix, Service de Pneumologie et Réanimation Médicale du Département R3S, Paris, France. ${ }^{10}$ Lane Fox Respiratory Service, Guy's and St Thomas' NHS Foundation, London, UK. ${ }^{11}$ Centre for Human and Applied Physiological Science, Faculty of Life Sciences and Medicine, School of Basic and Medical BioSciences, Kings College London, London, UK. ${ }^{12}$ Service of Pneumology, Hospital de Sabadell Corporació Parc Taulí, Universitat Autònoma de Barcelona, Centro de investigación Biomédica en Red (CIBERES), Sabadell, Spain. ${ }^{13}$ Dept of Internal Medicine, Pulmonary Diseases and Allergy, Medical University of Warsaw, Warsaw, Poland. ${ }^{14}$ Dept of Clinical, Integrated and Experimental Medicine (DIMES), Respiratory and Critical Care Unit, S. Orsola-Malpighi Hospital, Alma Mater University, Bologna, Italy. ${ }^{15} \mathrm{HP} 2$ Laboratory, INSERM U1042, Univ. Grenoble Alpes, and EFCR laboratory, Grenoble Alpes University Hospital, Grenoble, France. ${ }^{16}$ Dept of Intensive Care, Sleep Medicine and Mechanical Ventilation, Asklepios Fachkliniken Munich-Gauting, Gauting, Germany. ${ }^{17}$ Dept of Pneumology, University Medical Hospital, Freiburg, Germany. ${ }^{18}$ Dept of Pulmonary Diseases/Home Mechanical Ventilation, University of Groningen, University Medical Center Groningen, Groningen, The Netherlands. ${ }^{19}$ Institute of Social and Preventive Medicine, University of Bern, Bern, Switzterland. ${ }^{20}$ European Lung Foundation (ELF), Sheffield, UK. ${ }^{21}$ Dept of Pulmonology and Respiratory Intensive Care Unit, S. Donato Hospital, Arezzo, Italy. ${ }^{22}$ Dept of Pneumology, Cologne Merheim Hospital, Kliniken der Stadt Köln gGmbH, Witten/Herdecke University, Cologne, Germany.

${ }^{23}$ The first two authors contributed equally.

Correspondence: Raffaele Scala, Dept of Pulmonology and Respiratory Intensive Care Unit, S. Donato Hospital, Arezzo, Italy. Email: raffaele_scaladahotmail.com 
TABLE 1 Recommendations for PICO (target population-intervention-comparator-outcome) questions

Question

Should LTH-NIV be used in stable patients with COPD las compared to not using NIV)?

Should LTH-NIV be used after an episode of acute hypercapnic respiratory failure in patients with COPD las compared to not using NIV)?

When using LTH-NIV in COPD patients, should NIV settings be titrated to normalise or at least cause a significant reduction in $P_{\mathrm{aCO}}$ (as compared to titrating not according to $P_{\mathrm{acO}}$ levels)?

When using LTH-NIV in COPD patients, should we use fixed pressure modes las compared to adaptive or auto-titrating pressure modes)?

\section{Recommendation}

The ERS task force suggests LTH-NIV be used for patients with chronic stable hypercapnic COPD (conditional recommendation, low certainty evidence).

The ERS task force suggests LTH-NIV be used in patients with COPD following a life-threatening episode of acute hypercapnic respiratory failure requiring acute NIV, if hypercapnia persists following the episode (conditional recommendation, low certainty evidence).

The ERS task force suggests titrating LTH-NIV to normalise or reduce $\mathrm{PaCO}_{2}$ levels in patients with COPD (conditional recommendation, very low certainty evidence).

The ERS task force suggests using fixed pressure support mode as first-choice ventilator mode in patients with COPD using LTH-NIV (conditional recommendation, very low certainty evidence).

LTH-NIV: long-term home non-invasive ventilation; NIV: non-invasive ventilation; $P_{\mathrm{aco}}$ : partial pressure of carbon dioxide in arterial blood.

\section{Evidence summary and generation of clinical recommendations for PICO questions}

Following the GRADE procedure, the task force rated each outcome for its perceived importance for clinical decision-making (from a patient perspective) on a scale of 1-9, with mean scores of 7-9 indicating a "critical" outcome, 4-6 indicating "important but not critical" and 1-3 indicating "not important" [6]. The panel identified five "critical" outcomes, which would take priority in guideline decision-making for all PICO questions: mortality (short-term and long-term), hospitalisation, COPD exacerbation, dyspnoea, and health-related quality of life (HRQL). Data on non-critical outcomes (gas exchange, lung function, exercise tolerance, sleep quality) were also collected and considered, but were not prioritised in recommendation generation.

For the four PICO questions, the two methodologists (S. Oczkowski and B. Rochwerg) conducted searches of the medical literature with the assistance of a medical librarian, drawing upon and updating literature searches for each PICO question from existing systematic reviews on the topic of LTH-NIV in COPD [7-9]. Medline, Embase, Cochrane CENTRAL, CINAHL, and Web of Science were searched from January 2014 to January 2018 for English-language randomised controlled trials (RCTs) addressing the PICO questions. The search was updated in January 2019. The two methodologists screened the retrieved references for inclusion in the evidence summaries (supplementary figure S1).

Data from retrieved studies was entered into Revman v.5.3 software. For each PICO question, the methodologists, with input from the task force chairs, developed an evidence profile. Following GRADE principles, the task force rated the certainty of evidence for each outcome as "high," "moderate," "low," or "very low." The task force initially categorised the certainty of evidence for each outcome as high if it originated from RCTs and low if it originated from observational data. The quality of the evidence was subsequently downgraded by one or two levels if results from individual studies were at serious or very serious risk of bias [10], there were serious inconsistencies in the results across studies [11], the evidence was indirect [12], the data were imprecise [13], or publication bias was thought to be likely.

The task force developed recommendations for each PICO question by working through the GRADE Evidence to Decision Framework, which considers the quality of evidence, balance of desirable and undesirable effects, patient values and preferences, resource use, health equity, acceptability of an intervention, and feasibility of implementation $[14,15]$. Each recommendation was designated as "strong" or "conditional", using the phrasing "we recommend" for strong recommendations and "we suggest" for conditional recommendations [16]. Direction and strength of recommendations was decided by consensus at an in-person meeting on 17 September 2018 at the ERS International Congress in Paris.

\section{Manuscript preparation}

Following the generation of recommendations, the task force divided up into working groups, which for each PICO question summarised the recommendation, provided a narrative summary of the evidence (highlighting the largest and most relevant clinical trials for each PICO question), issues raised in the Evidence to Decision Framework, and a justification for the final recommendation considering the above, along with implementation considerations and future research directions. Editing and feedback on the manuscript was conducted electronically, and coordinated by the task force chairs. The final wording of all 
recommendations and justifications was agreed upon the entire task force, and the final manuscript was submitted to the ERS for review and approval.

\section{How to use these guidelines}

Due to limitations in the certainty of the available evidence, all four PICO recommendations are weak/ conditional, and therefore require consideration of individual preferences, resource considerations, technical expertise, and clinical circumstances prior to implementation in clinical practice. While we have tried to consider a wide spectrum of such factors when making recommendations, we cannot account for all conditions. For each recommendation, we discuss evidence limitations, issues when moving from evidence to recommendations, and implementation concerns. By reading these guidelines, and considering their applicability to their current situation, we hope these ERS guidelines will help patients, clinicians, policy makers, and other healthcare stakeholders to make rational, evidence-based, decisions with regard to the use of LTH-NIV in COPD, across a variety of settings. In table 2, we provide a high-level summary of how these guidelines can be applied $[17,18]$.

\section{Results}

Evidence summaries (including forest plots from meta-analyses) and Evidence to Decision Framework tables for each PICO can be found in the supplementary material.

PICO Question 1: Should LTH-NIV be used in stable patients with COPD las compared to not using NIV)?

Recommendation: The ERS task force suggests LTH-NIV be used for patients with chronic stable hypercapnic COPD (conditional recommendation, low certainty evidence).

\section{Background}

COPD can cause both hypoxaemic and hypercapnic CRF resulting in a high impact on mortality and economic burden of disease [19, 20]. So far, long-term oxygen therapy (LTOT), which has been shown to improve survival, is the standard of care in COPD patients with hypoxaemic CRF. COPD patients with chronic hypercapnia are more likely to be admitted to hospital, and once admitted experience a more rapid clinical deterioration $[21,22]$. The presence of hypercapnia has been shown to be a determinant of mortality [23-25].

Correcting hypercapnia may be an important intervention aiming at improving the prognosis of these patients. NIV in this setting is increasingly being used [26,27]. The favourable impact of the reduced lung hyperinflation on respiratory muscle workload and the increased ventilatory chemo-sensitivity to carbon dioxide have been demonstrated as the main mechanisms that may explain the effectiveness of NIV in stable hypercapnic COPD patients [28-30].

Many patients with advanced COPD have severe comorbidities (most importantly cardiovascular diseases), which independently impact their prognosis. Therefore, improving survival in hypercapnic COPD patients is

TABLE 2 Interpretation of strong and conditional recommendations

\begin{tabular}{|c|c|c|}
\hline & Strong recommendation & Weak recommendation \\
\hline For patients & $\begin{array}{l}\text { Most individuals in this situation would want the } \\
\text { recommended course of action and only a small } \\
\text { proportion would not. }\end{array}$ & $\begin{array}{l}\text { The majority of individuals in this situation would want the } \\
\text { suggested course of action, but many would not. }\end{array}$ \\
\hline For clinicians & $\begin{array}{l}\text { Most individuals should receive the recommended course } \\
\text { of action. Adherence to this recommendation according } \\
\text { to the guideline could be used as a quality criterion or } \\
\text { performance indicator. Formal decision aids are not } \\
\text { likely to be needed to help individuals make decisions } \\
\text { consistent with their values and preferences. }\end{array}$ & $\begin{array}{l}\text { Different choices are likely to be appropriate for different } \\
\text { patients and therapy should be tailored to the individual } \\
\text { patient's circumstances. Those circumstances may } \\
\text { include the patient or family's values and preferences. }\end{array}$ \\
\hline For policy-makers & $\begin{array}{l}\text { The recommendation can be adapted as policy in most } \\
\text { situations including for the use as performance } \\
\text { indicators. }\end{array}$ & $\begin{array}{l}\text { Policy making will require substantial debates and } \\
\text { involvement of many stakeholders. Policies are also } \\
\text { more likely to vary between regions. Performance } \\
\text { indicators would have to focus on the fact that adequate } \\
\text { deliberation about the management options has taken } \\
\text { place. }\end{array}$ \\
\hline
\end{tabular}

Reproduced from [14] with permission from the publisher. 
challenging. The inconsistent results evident between early studies [26] are likely due to a number of factors, including heterogeneous patient populations (including different degrees of hypercapnia), different NIV ventilators, varied ventilator settings and interfaces, wide range of NIV application time and patient compliance.

In 2009, McEvoy et al. [31] randomised 144 severe hypercapnic COPD patients either to NIV+LTOT or LTOT alone and demonstrated a slight survival benefit with NIV (median 28 months versus 20.5 months), but decreased HRQL. The mean inspiratory positive airway pressure (IPAP) was $13 \mathrm{cmH}_{2} \mathrm{O}$ and the mean expiratory positive airway pressure (EPAP) was $5 \mathrm{cmH}_{2} \mathrm{O}$, which corresponded to an inspiratory pressure support (difference between inspiratory and expiratory pressures) of $8 \mathrm{cmH}_{2} \mathrm{O}$. There was no decrease in partial pressure of carbon dioxide in arterial blood $\left(P_{\mathrm{aCO}_{2}}\right)$ level during follow-up. Subsequent clinical observation studies and randomised crossover clinical trials reported that targeting maximal reduction of carbon dioxide by high inspiratory pressures and high backup rates, or so called high-intensity NIV, improved gas exchange, lung function and respiratory muscle function [32-35]. A multicentre RCT included 195 patients with stable chronic hypercapnia (mean $P_{\mathrm{aCO}_{2}} 59 \mathrm{mmHg}$ in the NIV group and $58 \mathrm{mmHg}$ in the control group) and randomised patients to either LTOT alone or LTH-NIV in addition to LTOT ventilation targeting carbon dioxide reduction (mean IPAP of $22 \mathrm{cmH}_{2} \mathrm{O}$ with a mean EPAP of $5 \mathrm{cmH}_{2} \mathrm{O}$ employed to decrease $P_{\mathrm{aCO}}$ by at least $20 \%$ from baseline or to achieve $P_{\mathrm{aCO}_{2}}<48 \mathrm{mmHg}$ ). Results showed a 1-year survival benefit in patients randomised to LTH-NIV with an increase in HRQL [36].

Long-term prognosis following hospitalisation in COPD is poor, with 5-year mortality rates of around 50\% [37]. Therefore, one of the overall goals in the management of COPD is to minimise the number of disease-related hospitalisations, especially in those patients at high risk of developing acute hypercapnic respiratory failure (AHRF). LTH-NIV, initiated when the patient is in stable condition, may reduce the number of future hospitalisations in these patients. CuIN et al. [38] reported that overall hospital admissions were lower in patients randomised to NIV and LTOT as compared with LTOT alone $(-45 \%$ versus $+27 \%)$. In the study by KöHNLEIN et al. [36], a decrease in emergency hospital admissions was observed in the NIV group when compared to the control group (2.2 and 3.1 exacerbations per patient per year, respectively).

\section{Evidence summary}

Overall 13 RCTs (comparators to NIV are shown in the appendix) evaluated the effect of LTH-NIV on survival in stable hypercapnic patients with COPD; pooled analysis showed that NIV may have little effect on mortality (relative risk (RR) 0.86 , 95\% CI 0.58-1.27; low certainty) [31, 36, 38-48] or hospitalisations (mean difference (MD) 1.26 fewer hospitalisations, 95\% CI 0.08-2.59; low certainty) [36, 38, 49].

Although the presence of hypercapnia is one of the primary indicators to prescribe LTH-NIV in COPD, data suggest only a limited effect of NIV on this outcome. The pooled data over 12 RCTs showed that $P_{\mathrm{aCO}_{2}}$ decreased by $3.37 \mathrm{mmHg}$ (95\% CI 0.99 lower to 5.75 lower; moderate certainty) and partial pressure of oxygen in arterial blood $\left(P_{\mathrm{aO}_{2}}\right)$ increased by $3.09 \mathrm{mmHg}(95 \% \mathrm{CI} 1.45$ higher to 4.74 higher; moderate certainty) following NIV therapy [31, 36, 39, 41, 43-50]. This minimal effect may be due to the fact that ventilator settings were not titrated to target normal $P_{\mathrm{aCO}_{2}}$ levels. In a subgroup analysis of five RCTs in which NIV was used to target normal $P_{\mathrm{aCO}}$ levels, the $P_{\mathrm{aCO}_{2}}$ decrease was larger $(4.92 \mathrm{mmHg}$ reduction, 95\% CI 2.90 lower to 6.94 lower) [36, 39, 46-48]. There was no effect of NIV upon lung function as assessed by forced expiratory volume in $1 \mathrm{~s}\left(\mathrm{FEV}_{1}\right)$ (standardised mean difference (SMD) 0.07 higher, 95\% CI 0.14 lower to 0.27 higher; low certainty) or forced vital capacity (SMD 0.10 higher, 95\% CI 0.06 lower to 0.26 higher, low certainty) $[31,36,38,39,41,44,46-48,50]$.

Dyspnoea, exercise capacity, and HRQL are recognised as the most important patient-centred outcomes in the COPD population. Pooled analysis of five RCTs shows that NIV may decrease dyspnoea scores (SMD 0.51 lower, 95\% CI 0.06 lower to 0.95 lower; moderate certainty) [39, 43, 46, 47, 50]. NIV may improve exercise capacity and outcomes of pulmonary rehabilitation by resting chronically fatigued respiratory muscles, ameliorating lung mechanics, and daytime gas exchange [39]. Pooled analysis demonstrated an improvement in 6-min walk distance (6MWD) (MD $32.03 \mathrm{~m}, 95 \%$ CI 10.79-53.26 m; moderate certainty), which was higher than minimal important difference $(26 \mathrm{~m})$ for severe COPD, in those using NIV [36, 38, 39, 41, 45-47, 49-52].

Seven RCTs evaluated HRQL with a follow-up period ranging between 3 and 12 months; the pooled analysis demonstrated that HRQL was higher with NIV (SMD 0.49 higher, 95\% CI 0.01 lower to 0.98 higher; very low certainty) $[31,36,39,43,46,47,50]$. Included studies had to use one of the multiple validated scales/questionnaires in this population to assess HRQL. Whether NIV using high inspiratory pressure support values might be associated with higher HRQL remains unclear. In the multicentre study of KöHNLEIN et al. [36], Severe Respiratory Insufficiency (SRI) Questionnaire summary scale score, general health perception subscale of Short Form 36 (SF-36) and St George Respiratory Questionnaire (SGRQ) summary score improved more with NIV than with LTOT alone. 
The effect of LTH-NIV on sleep quality has been studied to a lesser extent and only based on subjective assessments. Pooled analysis suggested sleep efficiency was slightly lower in those randomised to NIV (SMD 0.55 lower, 95\% CI 1.13 lower to 0.03 higher; low certainty), but the clinical relevance of this is unclear due to heterogeneous measurements of sleep [38, 41, 46]. Minor adverse events such as discomfort, skin damage or rash were more common with NIV therapy (RR 10.35, 95\% CI 2.45-43.71; low certainty) when compared to LTOT alone. However, most of these effects are interface-related and may be straightforward to manage $[53,54]$.

\section{Justification}

The guideline panel decided on a conditional recommendation for NIV in the setting of stable chronic hypercapnic COPD patient. This recommendation was based on the evidence suggesting improvements in HRQL, dyspnoea, and exercise tolerance. Even though the certainty in evidence for these outcomes was low to moderate, all were felt to be very important to patients. The evidence also suggested the possibility of small reductions in mortality and hospitalisations, with LTH-NIV, though there was significant imprecision in the pooled effects. Overall, the benefits were felt to outweigh the potential harms including minor adverse events.

In terms of costs, frequent exacerbations and hospital readmissions account for the greatest part of economic burden in COPD patients, and economic data from the included trials suggest that NIV is cost-effective, especially in patients with frequent exacerbations and hospital admissions. Historically, LTH-NIV has been shown to reduce disease-related cost by decreasing the rate of outpatient visits, the hospital admissions, and the length of stay in the hospital [55]. The overall cost-effectiveness of NIV therapy depends on further variables, such as strategy for initiating NIV and close monitoring and follow-up including home care. LTH-NIV has evolved over the past 20 years and today's technology gives us the opportunity to monitor, even remotely, many physiological parameters by built-in software systems of NIV devices [56]. While in higher developing countries there has been a widespread use of LTH-NIV, in the countries with lower income economies, financial constrains may be a major limiting factor for patients who may benefit of LTH-NIV, including those with stable COPD [57].

PICO Question 2: Should LTH-NIV be used after an episode of acute hypercapnic respiratory failure in patients with COPD (as compared to not using NIV)?

Recommendation: The ERS task force suggests LTH-NIV be used in patients with COPD following a life-threatening episode of acute hypercapnic respiratory failure requiring acute NIV, if hypercapnia persists following the episode (conditional recommendation, low certainty evidence).

\section{Background}

Severe COPD patients with chronic hypercapnia are most likely to experience re-hospitalisation after a life-threatening episode of acute on chronic respiratory failure. These so-called "revolving doors" patients, are often discharged with a $P_{\mathrm{aCO}}$ above $55 \mathrm{mmHg}$ after a decompensated or compensated episode of respiratory acidosis due to $\mathrm{COPD}$ exacerbation on the background of at least two hospital admission episodes in the previous year $[55,58]$.

Four RCTs have evaluated the use of LTH-NIV after AHRF [59-62]. The first clinical trial randomised 40 patients with severe stable COPD $\left(P_{\mathrm{aCO}_{2}} \geqslant 55 \mathrm{mmHg}\right)$ after hospital discharge from AHRF to NIV or standard treatment for 2 years. The use of NIV was not associated with a reduction in mortality but improved several physiological (e.g. $P_{\mathrm{aCO}_{2}}$ and $P_{\mathrm{aO}}, 6 \mathrm{MWD}$, mean pulmonary artery pressure), patient-centred (e.g. anxiety, depression, dyspnoea) and healthcare centred (e.g. hospitalisation rates) outcomes [59]. The second trial was a pilot RCT designed to compare continuation of NIV from hospital to home, with sham continuous positive airway pressure (CPAP) used as control, in severe COPD patients who had survived an acute episode treated with NIV and showed persistent hypercapnia at discharge (mean $P_{\mathrm{aCO}}$ $\sim 50 \mathrm{mmHg}$ ). A total of 47 patients were randomised and the proportion of patients developing an acute exacerbation during the time course of the study was statistically higher in the CPAP group. Of note, 8/23 (35\%) of the LTH-NIV patients were withdrawn from the study before completion [60].

Two larger RCTs investigated the clinical efficacy of NIV as a bridging treatment from hospital to the home following a life-threatening exacerbation of COPD requiring acute NIV. In the RESCUE trial, 201 COPD patients admitted to hospital with a life-threatening episode of AHRF and prolonged hypercapnia (mean $P_{\mathrm{aCO}_{2}} \sim 48 \mathrm{mmHg}$ ) greater than $48 \mathrm{~h}$ after termination of ventilatory support were randomised to NIV in addition to LTOT or LTOT alone. After 1 year, there was no difference between the two groups in the primary outcome of time to readmission or death. Although NIV was effective in reducing daytime and night-time $P_{\mathrm{aCO}}$, a similar reducing in $P_{\mathrm{aCO}}$ was observed in the control group [61]. 
The HOT-HMV trial studied $116 \mathrm{COPD}$ patients with persistent hypercapnia $\left(P_{\mathrm{aCO}_{2}}>53 \mathrm{mmHg}\right)$ at 24 weeks after a life-threatening episode of acute on chronic respiratory failure treated with acute NIV, were randomised to receive LTH-NIV, in addition LTOT, or LTOT alone. The NIV+LTOT group, compared to the LTOT group, resulted in an increased time to readmission or death within 12 months (4.3 months versus 1.4 months) [62].

It is difficult to translate the results from the earlier studies into advice for the practising clinician due to the small sample sizes, lack of standard definition of acute COPD exacerbation, and lower pressure support levels compared to the later studies. However, major clinical interest was raised by the latter trials, which despite similar trial design and primary outcome measure had differing results in terms of admission-free survival. It is likely that the higher level of $P_{\mathrm{aCO}}$ at enrolment (mean $48 \mathrm{mmHg}$ versus $53 \mathrm{mmHg}$ ), the higher exacerbations rate prior to enrolment and the timing selection of patients with persistent hypercapnia at 2-4 weeks following a life-threatening exacerbation were major determinants of the enhanced outcome in the HOT-HMV trial. Conversely, the early within-hospital assessment of hypercapnia in the RESCUE trial may have led to the inclusion of a subset of patients with spontaneously reversible hypercapnia who do not take benefits from LTH-NIV treatment and consequently a better prognosis. The trajectory of recovery of hypercapnia is likely to have an influence on the outcome and the timing of this recovery needs clarification [24].

Another RCT evaluated the effects of stopping NIV after 6 months post-hospitalisation, finding that patients who remained hypercapnic after 6 months of therapy had clinical worsening and reduced 6 MWD after stopping NIV, compared to those who continued, indicating the importance of careful selection of patients who will continue to benefit from LTH-NIV [63].

\section{Evidence summary}

Use of LTH-NIV after AHRF was not associated with a reduction in mortality (RR 0.92, 95\% CI 0.67 to 1.25; low certainty), but may reduce exacerbations (SMD $0.19 \mathrm{SD}, 95 \% \mathrm{CI}-0.40$ to $0.01 \mathrm{SD}$; low certainty) and hospitalisations (RR 0.61, 95\% CI 0.30-1.24; very low certainty) though the study by CHEUNG et al. [60], at high risk of bias, and with unclear definition of acute exacerbation, makes interpretation of these outcomes difficult. Reassuringly, sensitivity analysis excluding CHeung et al. [60] does not significantly affect the conclusions made for these outcomes. Similarly, NIV may be associated with improvements in dyspnoea scores measured using Medical Research Council Dyspnoea score (MD 0.8 points lower, $95 \%$ CI 2.17 lower to 0.58 higher; low certainty) and HRQL measured using SRI (MD 2.89 higher, 95\% CI 1.03 lower to 6.8 higher) but these results are limited by imprecision and are of low certainty. NIV likely reduces $P_{\mathrm{aCO}_{2}}(\mathrm{MD}-3.41 \mathrm{mmHg}, 95 \% \mathrm{CI}-4.09$ to -2.73 ; moderate certainty).

\section{Justification of recommendation}

The recommendation was primarily based upon the desirable effects of LTH-NIV after a life-threatening episode of acute on chronic respiratory failure, which suggest a small potential reduction in exacerbations and hospitalisations, though the overall certainty of evidence is low, primarily due to imprecision as well as reservations about the risk of bias. The task force considered indirect evidence from PICO question 1 with regard to minor adverse effects and resources required to help to inform the recommendations here, and noted that reassuringly similar desirable effects of NIV were seen in the COPD population both in stable (PICO question 1) and in post-AHRF phase (PICO question 2), with few undesirable effects seen. Other outcome data from PICO question 1 was used for question 2 analysis or recommendation generation. Similarly, the task force considered that the potential significant variability in values and trade-offs between mortality and HRQL with the use of NIV may play a role in shared decision-making about its use in this population, and ultimately the acceptability of NIV as an intervention. The task force considered the resources used similar to that in PICO question 1, though the feasibility of initiating NIV post-exacerbation may be higher, as in some centres clinical pathways exist post-discharge to facilitate initiation of LTH-NIV. Considering all of the above in light of the limitations of the evidence, the task force panel chose to make only a conditional recommendation for the use of LTH-NIV after AHRF. Finally, there was discussion that patients may continue to improve for several weeks post-exacerbation; for this reason, reassessment of hypercapnia 2-4 weeks after the initial episode, as was done in the HOT-HMV trial, could be considered to identify those patients who are most likely to benefit from LTH-NIV.

PICO Question 3: When using LTH-NIV in COPD patients, should NIV settings be titrated to normalise or at least cause a significant reduction in $\mathrm{P}_{\mathrm{acO}}$ las compared to titrating not according to $\mathrm{P}_{\mathrm{aCO}}$ (evels)?

Recommendation: The ERS task force suggests titrating LTH-NIV to normalise or reduce $P_{a C O_{2}}$ levels in patients with COPD (conditional recommendation, very low certainty evidence). 


\section{Background}

In the past two decades, a number of published RCTs aimed at exploring the role of LTH-NIV in those with hypercapnic COPD; however, most did not specifically target normalisation or significant reduction in $P_{\mathrm{aCO}}$ or directly address nocturnal alveolar hypoventilation. High-intensity NIV, a form of pressure-limited controlled ventilation, that combined stepwise titration of IPAP up to $30 \mathrm{cmH}_{2} \mathrm{O}$ with an high backup rate just below the patient's spontaneous breathing frequency, was introduced as a novel therapeutic option in an attempt to maximally decrease elevated $P_{\mathrm{aCO}_{2}}$ to normal levels and, at the same time, to achieve the total control of the patient's spontaneous respiratory activity aiming for substantial rest of the diaphragm $[35,64,65]$. Given to the greater capability of correcting nocturnal alveolar hypoventilation, high-intensity NIV has been reported to be more efficient in terms of clinical and physiological benefits (reduction of nocturnal and diurnal $P_{\mathrm{aCO}_{2}}$ levels; improvement in $\mathrm{FEV}_{1}$, patient-reported exercise-related dyspnoea score, 6MWD and HRQL) than conventional "low-intensity" NIV. Paradoxically, delivery of higher levels of pressure support was associated with better compliance to the treatment, probably as consequence of a greater subjective benefits perceived by chronically symptomatic patients [64-67].

A strategy based on the combination of high pressure support levels and low backup rate, termed "high-pressure" NIV, has been shown to provide the same physiological and clinical improvement in stable hypercapnic COPD compared with "high-intensity" NIV, suggesting that the use of a high backup rate is not necessary to achieve these benefits in such patients [67]. However, the number of patients in this study was considerably small requiring further investigations.

In consideration of the greater haemodynamic impact of "high-intensity" NIV as compared to "low intensity" NIV, positive intrathoracic swing pressure-induced decrease in right heart preload and elevated lung volume-induced increase in pulmonary vascular resistance, detrimental cardiovascular effects (i.e. reduced cardiac output) could develop under very high IPAP levels in very selected phenotypes of COPD patients, especially if pre-existing severe cardiovascular diseases coexist [64, 65]. However, the clinical significance of these effects needs further evaluation. Although it appears that high inspiratory pressure NIV leads to a reduction in hypercapnia, the impact on some patient important outcomes, such as sleep quality, is less certain $[66,67]$.

Finally, it should be considered that the definition of hypercapnia used amongst the studies targeting NIV to $P_{\mathrm{aCO}}$ normalisation in stable hypercapnic COPD patients was quite different, sometimes with very low mean baseline $P_{\mathrm{aCO}_{2}}$ levels [61]. Independently from the baseline degree of hypercapnia, a normalisation of elevated $P_{\mathrm{aCO}}$ levels is unlikely to be achieved in all COPD patients even under high IPAP levels.

\section{Evidence summary}

Even though one short-term trial reported physiological benefits of NIV targeted to reduce chronic hypercapnia [34], we did not find any long-term RCTs directly comparing LTH-NIV strategies targeting $P_{\mathrm{aCO}_{2}}$ reduction in those with chronic COPD versus those that did not. For this reason, to address this question, we considered subgroup analysis from PICO question 1 comparing studies that targeted normalisation of $P_{\mathrm{aCO}}$ as compared to studies that did not target normalisation.

Pooled analysis of five RCTs demonstrated that while "high-intensity" NIV decreases $P_{\mathrm{aCO}}$ levels at 6 weeks ( $\mathrm{MD}-4.93 \mathrm{mmHg}, 95 \% \mathrm{CI}-7.43$ to -2.42 ; low certainty) as compared to "low-intensity" NIV, there was no effect on HRQL as assessed by the SRI (MD 0.95 points higher, 95\% CI 8.33 lower to 6.42 higher; low certainty) in the "high-intensity" subgroup [34, 64-66]. There was no effect demonstrated with "high-intensity" NIV on $\mathrm{FEV}_{1}$ (MD $0.04 \mathrm{~L}$ higher, 95\% CI 0.34 lower to 0.42 higher; low certainty), 6MWD (MD $14 \mathrm{~m}$ higher, 95\% CI 70.42 lower to 98.42 higher; low certainty), sleep comfort measured by visual analogue scale scale (MD $1 \mathrm{~cm}$ higher, 95\% CI 28.42 lower to 30.42 higher; very low certainty) or $P_{\mathrm{aO}_{2}}$ levels at 6 weeks (MD $3.4 \mathrm{mmHg}$ higher, 95\% CI 2.39 lower to 9.19 higher; low certainty).

\section{Justification}

The task force panel decided on a conditional recommendation for targeted reduction of $P_{\mathrm{aCO}_{2}}$ in COPD patients with persistent hypercapnic respiratory failure. Although the benefit was uncertain, this recommendation was driven by the minimal potential harms of targeted $P_{\mathrm{aCO}_{2}}$ reduction [64, 65], though it is recognised that this is unlikely to be achieved in all patients. While there is low certainty of evidence of benefit, the anticipated harms have not been clearly demonstrated, and as such the panel felt the overall balance favoured the intervention. Setting NIV to target a reduction in $P_{\mathrm{aCO}}$ may require more time spent in hospital [34], and therefore possibly increase costs and decrease feasibility of NIV; however, adherence was significantly better using this strategy. 
PICO Question 4: When using LTH-NIV in COPD patients, should we use fixed pressure modes (as compared to adaptive or auto-titrating pressure modes)?

Recommendation: The ERS task force suggests using fixed pressure support mode as first-choice ventilator mode in patients with COPD using LTH-NIV (conditional recommendation, very low certainty evidence).

\section{Background}

In general, classical modes of LTH-NIV comprise both pressure-targeted and volume-targeted NIV. During pressure-targeted NIV, the inspiratory pressure is set, while the delivered inspiratory volumes vary according to the impedance of the respiratory system and the patient's respiratory efforts. In contrast, during volume-targeted NIV, a predetermined inspiratory volume is set, while inspiratory pressures are variable. Accordingly, the physiological advantage of volume-targeted NIV is the stability of tidal volume, while pressure-targeted NIV is advantageous regarding leak compensation when the inspiratory flow is increased in case of leak-related dropping pressure. Even though physiological and short-term clinical studies indicate that pressure-targeted NIV is better tolerated due to less varying peak inspiratory pressures, both modes are reported to be comparably effective in providing NIV, though the majority of studies have investigated heterogeneous patient cohorts and not exclusively patients with COPD [68-75]. Long-term studies comparing currently available ventilator modes do not exist, limiting the potential for strong conclusions. However, nearly all studies providing evidence for the use of LTH-NIV in COPD in PICO question 1 and PICO question 2 used pressure-targeted modes rather than volume-targeting modes of NIV, making pressure volume modes the de facto standard in LTH-NIV for COPD.

Recent developments seek to combine the advantages of volume- and pressure-targeted NIV, while avoiding their disadvantages [76]. In addition, there is a physiological rationale supporting the interest in continuously adapting ventilator parameters to fluctuating patient needs during the night and also over the long term. In addition, upper airway patency may vary with body position and sleep stage, especially during rapid eye movement (REM) sleep. Respiratory mechanics may also change as an individual's disease worsens over time. Ideally, LTH-NIV aims to deliver the adequate inspiratory pressure support to achieve targeted minute ventilation and sufficient expiratory pressure for complete stabilisation of the upper airway.

The so-called adaptive or auto-titrating modes have been designed to achieve these objectives even if applied with different software. There was also the hope that automatically identifying adequate settings for a given patient would allow implementation of NIV in non-specialised centres, thus favouring the widespread application of the technique. Conversely, there are certain complications and pitfalls related to these hybrid modes as depicted in detail elsewhere [76].

\section{Evidence summary}

Six RCTs compared adaptive or auto-titrating pressure modes (e.g. iVAPS, Resmed, Australia; AVAPS, Philips, USA) to classical pressure support modes [77-82]. These studies were generally not blinded, and of short duration, prohibiting assessment of long-term outcomes such as mortality or hospitalisations. Six studies demonstrated that use of adaptive or auto-titrating modes may result a small reduction in $P_{\mathrm{aCO}_{2}}$ (MD $1.95 \mathrm{mmHg}$ lower, 95\% CI $4.29 \mathrm{mmHg}$ lower to $0.40 \mathrm{mmHg}$ higher; low certainty) and little to no difference in oxygenation (SMD $-0.04,95 \%$ CI -0.33 to 0.26 ; low certainty) compared to conventional NIV. Adaptive or auto-titrating modes did not significantly improve HRQL using the SGRQ or the SRI (SMD $0.28,95 \%$ CI -0.66 to $0.10 \mathrm{SD}$; low certainty evidence), sleep quality measured using a variety of validated instruments (SMD - $0.14,95 \% \mathrm{CI}-0.53$ to $0.26 \mathrm{SD}$; very low certainty), or exercise tolerance (SMD $-0.1,95 \%$ CI -0.51 to 0.30 ; low certainty) compared to conventional fixed modes of NIV.

Adherence to NIV was equivalent when comparing adaptive or auto-titrating modes to conventional assist modes in five studies [77-81]. Regarding patient-centred outcomes, no improvement in self-reported tolerance $[78,80]$ or self-reported comfort $[77,78]$ was achieved with the newer modes. One study used a specific questionnaire to assess acceptability, but again no difference was demonstrated [82].

\section{Justification}

While the pooled analyses suggests a small potential benefit to adaptive or auto-titrating modes in $P_{\mathrm{aCO}}$ reduction, and acceptable adherence, our recommendation is conditional for fixed modes owing to substantial uncertainty of the effects of adaptive or auto-titrating modes, and the heterogeneity across studies for algorithms, brands of devices and lack of detailed information regarding the way adaptive modes function. Moreover, there is uncertain risk of harm with adaptive/auto-titrating modes when there is severe air leak, a common clinical scenario, as adaptive modes require the ventilator to accurately measure/estimate tidal volumes [76]. This raises safety concerns, as inappropriate low volumes could be 
delivered in this situation, resulting in hypoventilation. The short follow-up of the available trials means there is little data on this potentially serious risk. Furthermore, there may be substantial additional cost to patients to upgrade to a machine equipped with these newer ventilatory modes if a patient is already using an older ventilator; however, for patients starting with new devices the costs may be similar.

\section{Narrative question 1: Do other factors impact the effectiveness of LTH-NIV in COPD? \\ Patient-related factors \\ Age and comorbidities}

The impact of age of a patient on outcome of LTH-NIV has not been evaluated. Previous RCTs excluded patients above 75 or 80 years old [31,38,44]; more recently, studies have not used age exclusion criteria, but the elderly consisted of a very small proportion of the eligible subjects and the average age was around 65 years [36, 61, 62]. KöHnLEIN et al. [36] excluded patients with "impaired general condition that could preclude regular follow-up visits" when evaluating survival benefit in stable COPD patients. Borel et al. [83], in multivariate analysis of a prospective, observational survey (213 subjects, oldest age patient 76 years old) showed that older age is independently associated with poorer prognosis. Age itself cannot be considered an exclusion criterion. However, associated mental and/or physical disability and a lack of sufficient help of caregivers may significantly impair the efficacy of LTH-NIV. This issue should be addressed by the providers.

All but one RCT [61] excluded subjects with comorbidities such as malignancy, severe heart failure, obstructive sleep apnoea syndrome (OSAS), obesity and unstable angina [31, 36, 38, 44, 48, 60, 62, 63]. As a result, the studied population was very homogenous, comprising patients purely with COPD: so-called "respiratory COPD" [84]. It is, therefore, difficult to answer whether the coexistence of the main COPD comorbidities has any impact on efficacy of LTH-NIV. However, the pathophysiological effect of airway positive pressure can provide additional positive outcomes in COPD patients with comorbidities: specifically, patients with pulmonary congestion or central apnoea due to heart failure, hypoventilation in obese patients and OSAS. BOREL et al. [83] demonstrated better prognosis in obese subjects versus non-obese; moreover, the effect was independent of coexisting OSAS. There was no benefit of the use of LTH-NIV in COPD patients with heart failure, but it is noteworthy that in the cohort of BorEL et al. [83] the proportion of subjects with heart failure and hypertension was higher in the obese group with better prognosis than in the non-obese group with worse outcomes.

Cachexia is a frequent comorbidity in COPD and is associated with respiratory muscle atrophy-induced dysfunction [84]. BOREL et al. [83] found that lower body mass index (BMI) is independently associated with poorer prognosis. In the majority of RCTs, average BMI was about $25 \mathrm{~kg} \cdot \mathrm{m}^{-2}$, and subjects with BMI $<19 \mathrm{~kg} \cdot \mathrm{m}^{-2}$ were usually not enrolled. However, two RCTs on LTH-NIV after acute exacerbation, which enrolled subjects with relatively low BMI $\left(19 \mathrm{~kg} \cdot \mathrm{m}^{-2}\right.$ [60] and $21 \mathrm{~kg} \cdot \mathrm{m}^{-2}$ [62]), demonstrated significant prolongation of the time to readmission due to acute exacerbation. Finally, a previous study has demonstrated weight gain following NIV commencement, and this was particularly true for cachectic patients [85]. This suggests that cachectic COPD patients who usually suffer from severe dyspnoea and weakness of the respiratory muscles may benefit from LTH-NIV.

In summary, comorbidities are not contraindications to LTH-NIV. Obese patients and patients with overlap syndrome (COPD and OSAS) make up the subgroup that may benefit the most from LTH-NIV. The initiation of LTH-NIV in patients with advanced COPD requires a high amount of motivation and cooperation and it is necessary to allow the patient sufficient time to adapt to NIV, especially when high inspiratory pressures are used [2].

\section{Adherence}

Adherence to therapy has a key role in the efficacy of LTH-NIV. However, there is no clear picture of the relationship between the number of hours per night of use and outcomes [38]. Mean compliance in the RCTs which showed survival benefits of LTH-NIV was 4.5 [31] and about $6 \mathrm{~h}$ per day [36], respectively. However, McEvoy et al. [31] found the survival advantage was found to be better in the per-protocol analysis (subjects with compliance $>4 \mathrm{~h}$ per day, $60 \%$ of all) than in intention-to-treat analysis. Conversely, STRUiK et al. [61] found no correlation between number of hours of NIV per night and decrease in $P_{\mathrm{aCO}_{2}}$. One uncontrolled trial demonstrated that adherence higher than $5 \mathrm{~h}$ per day improves survival in obese, but not non-obese, COPD patients [83]. Interestingly, authors found high adherence over $9 \mathrm{~h}$ per day was a marker of worse prognosis. One explanation is increased dependence on NIV is due to the worsening of the patient status. A minimum use of $5 \mathrm{~h}$ per night was found to be needed to reach significant change in $P_{\mathrm{aCO}}$ after 3 months of treatment in the meta-analysis using individual patient data of all studies on LTH-NIV [7]. In conclusion, $5 \mathrm{~h}$ of NIV per day would be a reasonable target; however, if patients do not achieve this, they may still receive clinical benefit. 
Equipment related factors

Many technical details with home ventilators, masks, tubes and humidification can decrease tolerance, efficacy and produce secondary effects, affecting adherence to the treatment $[1,86]$. NIV can be delivered at home for COPD patients through nasal, oronasal or full face mask. Although nasal masks offer greater patient comfort, they often have the problem of oral leaks, especially during sleep, which in turn influence alveolar ventilation and sleep quality [1]. Currently, prescribers in Europe reported using oronasal masks more often as alveolar ventilation is much better with these than nasal masks, especially when high IPAP levels are used [27, 87-89]. Full face masks can serve as a supplement or an alternative to existing ventilation masks in the event of problems with pressure ulcers. Patients with frequent cough or abundant secretions, either chronically or during an exacerbation, usually do not tolerate oronasal masks and may use a nasal mask temporarily. There is no evidence that a particular interface guarantees greater benefit from LTH-NIV, so the choice should be carefully tailored to the patient choice.

Home ventilators can be used with a single circuit ventilation system with vented masks. The advantage of single circuits is their lower weight compared to double circuit systems and simpler handling, which is particularly important at home.

Circuits with expiratory valves can be also used. The expiration valve is located within the tubing circuit or in the ventilator. In an experimental study, the use of active valve circuits was associated with more efficient $P_{\mathrm{aCO}}$ reduction when compared to leak port circuits [90], but it remains unclear how this is translated in clinical long-term application.

Ventilators without battery will be used when NIV is used for less time in each 24-h period. If the patient uses it for a longer duration (approximately $12 \mathrm{~h}$ per day, depending on individual circumstances) a ventilator with internal battery should be considered.

However, upgrading to a device with an internal battery does incur a significantly greater cost and this added burden may be not be feasible across a range of health systems in lower income economies. In fact, the ventilator-dependence threshold for transitioning to a device with an internal battery may be variable among the different countries [57].

Active humidification is sometimes suggested for NIV [91] as it may improve adherence and comfort, but there is no clear consensus on whether additional heat and humidity are always necessary when the upper airway is not by-passed, such as in NIV. Thus, it could be added if mucosal dryness becomes an issue. Two systems, active humidification through a heated humidifier $(\mathrm{HH})$ and passive humidification through a heat and moisture exchanger (HME), are available for warming and humidifying gases. Use of an HME is not beneficial in patients on NIV with intentional leaks, as the patient does not exhale enough tidal volume to replenish heat and moisture to adequately condition the inspired gas. HME may add additional work of breathing and use of an $\mathrm{HME}$ increases dead space and $P_{\mathrm{aCO}}$, and may increase ventilatory requirements [92]. With $\mathrm{HH}$ and intentional leaks, aerosolised contaminated condensate may increase the risk for infection.

\section{Additional therapies}

Supplemental oxygenation (LTOT+NIV)

Usually, CRF in the course of COPD starts with hypoxaemia and the first modality of treatment is LTOT, which improves survival [93]. The aim of oxygen therapy when added to LTH-NIV is to maintain adequate oxygenation if this is not achieved by the correction of hypoventilation. The clinician needs to be aware that the dose of oxygen which maintains oxygen saturation when awake can be insufficient during sleep with NIV.

\section{Pulmonary rehabilitation}

Pulmonary rehabilitation (PR) is a cost-effective treatment for patients with COPD with the associated benefits of improved HRQL and increased exercise capacity [94-96]. Studies showed an increase in exercise tolerance with the addition of NIV whilst exercising [97-101]. Unfortunately, according to recent systematic reviews and British Thoracic Society (BTS) guidelines the benefits from using NIV during exercise training as add-on treatment to PR in patients with COPD were unclear, probably because of insufficient pressures applied [102-105].

Conversely, the addition of nocturnal LTH-NIV to daytime PR in COPD stable patients is likely to give more benefits. GARROD et al. [43] performed the first study evaluating nocturnal NIV+PR compared to PR alone in non-hypercapnic hypoxaemic patients. They showed that arterial blood gas (ABG) values improved in patients in the NIV+PR group, who also had a greater improvement in exercise tolerance and HRQL than those in group with PR alone. DuIverman et al. [106] compared PR to PR+NIV over 2 years in hypercapnic severe COPD in an RCT. PR+NIV improved HRQL, mood, dyspnoea, ABG values, exercise 
tolerance and prevented as rapid decline of lung function. However, exacerbation frequency and mortality were not significantly different between groups. COQUART et al. [107] found that home-based PR in patients with NIV is feasible. They compared PR in patients on nocturnal CPAP, nocturnal NIV, LTOT or no additional equipment. They showed that the NIV group significantly increased walking distance when compared to the other conditions. Marquez-Martin et al. [50] performed an RCT over 12 weeks comparing groups allocated to either PR, NIV or PR+NIV. Patients reportedly received 6 to $8 \mathrm{~h}$ per night of NIV. There were improvements in exercise capacity for the PR and PR+NIV groups but not the NIV group alone. There were improvements in ABG values for the NIV and NIV+PR groups, and the improvement was greater in the NIV+PR group.

There is a lack of data on enhancing LTH-NIV with PR; however, the addition of PR to nocturnal NIV in COPD may have potential benefits of increasing exercise capacity and HRQL.

Strategies to manage bronchopulmonary secretions

Consideration may be given to the use of airway clearance techniques for patients with COPD in both acute and stable disease; however, current studies suggest that the benefits achieved may be small [108]. Airway clearance techniques in COPD patients may decrease hospitalisations [109]. It is logical that being free of secretions would help with adherence to NIV as there would be less coughing, which can be a barrier to the use of ventilatory support. Moreover, being secretion-free reduces the resistance of airways, and consequently improves ventilation, which may also contribute to improvements in ABG values. Mechanical insufflation-exsufflation devices are used in patients with NIV. There is no evidence that these devices increase cough effectiveness in patients with COPD [110], unless they have respiratory muscle weakness. However, no studies have compared LTH-NIV versus LTH-NIV and airway clearance techniques in patients with COPD.

Mucolytics are potentially useful for the management of COPD in patients that have tenacious secretions. A Cochrane review [111] and meta-analysis [112] found that mucolytic therapy led to an increase possibility of being exacerbation-free compared to placebo. However, due to much heterogeneity between the studies, these data should be interpreted with caution. More recently, a European Respiratory Society/American Thoracic Society guideline [113] recommends an oral mucolytic in patients with moderate to severe airflow obstruction and exacerbations despite optimal inhaled therapy. No studies have compared LTH-NIV versus LTH-NIV and mucolytics in patients with COPD. However, it would seem reasonable to treat patients who complain of secretion retention to prevent secretions being a barrier to LTH-NIV in COPD.

Narrative question 2: How can clinicians monitor and follow-up patients during LTH-NIV? The recommendation of using high inspiratory pressure levels in COPD receiving LTH-NIV is to achieve a substantial decrease in $P_{\mathrm{aCO}}$. The key thing is to document a reduction in $P_{\mathrm{aCO}}$ during NIV. More sophisticated monitoring should be reserved for cases when expected results with NIV are not achieved. In a recent preliminary study, pressure titration with simplified methods in a cohort of COPD-OSAS overlap patients achieved similar clinical effectiveness in terms of change in 3-month daytime $P_{\mathrm{aCO}}, \mathrm{HRQL}$ and sleep quality compared to polysomnography-based pressure titration [114].

The American Sleep Association recommends for the follow-up the assessment of clinical symptoms and an analysis of oxygenation and $P_{\mathrm{aCO}}$ values during wakefulness and quiet breathing [115]. Management as outpatients, with associated cost savings, is possible following a strict protocol based on symptoms, ABG assessment, and simple monitoring tools [116]. Clinical evaluation should be focused on symptoms of nocturnal hypoventilation and discomfort with the device [1].

Nocturnal gas exchange monitoring (continuous oxygen saturation and transcutaneous carbon dioxide tension $\left(P_{\mathrm{tcCO}_{2}}\right)$ measurement) is common in clinical practice $[1,61,62,117,118]$. Home-ventilated COPD patients often receive oxygen therapy with NIV, negating the usefulness of oxygen saturation with pulse oximetry monitoring for detecting nocturnal hypoventilation. On the other hand, isolated values of daytime $P_{\mathrm{aCO}_{2}}$ cannot rule out nocturnal hypoventilation, particularly in neuromuscular patients [119]. Nocturnal monitoring with $P_{\mathrm{tcCO}_{2}}$ allows detecting nocturnal hypoventilation as there is minimal drift with modern devices [120]. In the recent HOT-HMV trial, there was a statistically significant reduction in nocturnal $P_{\mathrm{tcCO}}$ levels on the night after initiation of NIV, which reportedly persisted to 12 months [62]. Finally, uncontrolled nocturnal hypoventilation seems to be related to increased risk of exacerbations and pulmonary hypertension [121]. End tidal carbon dioxide monitoring should never be used to approximate $P_{\mathrm{aCO}_{2}}$ in patients with COPD during spontaneous breathing or NIV, and is even less reliable in patients with invasive ventilation $[122,123]$

In recent years, improvements introduced by manufacturers in their models have led these devices to act both as ventilators and monitors. Data stored in the internal memory of such devices provide information 
TABLE 3 Future high-priority research questions

PICO Question 1: LTH-NIV in chronic stable hypercapnic COPD

\section{PICO Question 2: LTH-NIV in COPD following an episode of acute hypercapnic respiratory failure}

\section{PICO Question 3: LTH-NIV to normalise or reduce $P_{\mathrm{acO}}$}

PICO Question 4: Fixed pressure versus new adaptive/auto-titrating modes in LTH-NIV
Strategies for initiating NIV. It is obvious that ventilator setting and acclimatisation to NIV are crucial for effectiveness, including better adherence. NIV may be initiated in the hospital or at home. In-hospital initiation can be easily performed in some centres; however, it is more expensive and complex.

The benefits of NIV in subgroups of patients with COPD. The variability of both adherence and treatment response may vary according to different clinical phenotypes. Indeed, it seems that the response is better in those patients with $P_{\mathrm{aCO}}>50 \mathrm{mmHg}$ and $P_{\mathrm{aCO}}$ reduction to normal following NIV. A phenogrouping strategy of hypercapnic COPD subgroups is needed for better defined the populations to be prioritised in further studies.

The impact of comorbid conditions in this population e.g. the effect of obesity, OSA-overlap, cardiovascular diseases, and clinical frailty upon clinical outcome.

Assessment of other underestimated factors, such as lack of social support and patient-ventilator asynchrony, which may impact the effectiveness of LTH-NIV.

Cost effectiveness studies reporting the health economic value of LTH-NIV in chronic stable COPD. Developing more accurate criteria for identifying patients who are likely to benefit from LTH-NIV, such as severity of illness (hypothesis that treatment of higher $P_{\mathrm{acO}}$ at initiation will drive greater clinical benefits), trajectory of hypercapnia recovery after exacerbation (as some patients return to eucapnia more rapidly than others) and treatment response (e.g. early reduction in $P_{\mathrm{acO}_{2}}$ level after starting LTH-NIV, with the hypothesis that greater reduction in $P_{\mathrm{acO}}$ will drive greater clinical benefit).

Physiological and biological mechanisms of action of LTH-NIV: physiological mechanisms determining reduction in $P_{\mathrm{acO}}$; the biological effects of $P_{\mathrm{acO}}$ reduction in chronic hypercapnia upon the immune system, pulmonary vasculature and skeletal muscle; biological mechanisms determining reduction in exacerbation; and physiological mechanisms determining enhanced sleep quality.

The effects of NIV upon mental health and cognition upon patients, including effects upon HRQL and, cognitive function after an acute hypercapnic respiratory failure, the relationship between HRQL and cognitive function upon adherence and acceptability of LTH-NIV.

Health service delivery research to promote the delivery of LTH-NIV after an acute hypercapnic respiratory failure to the right patient at the right time and prevent the "overuse" or "underuse" of the treatment.

Assessment of novel home treatments, e.g. high flow humidified nasal oxygen, that are capable of reducing $P_{\mathrm{acO}}$ in stable hypercapnic COPD patients.

The impact of NIV ventilator strategy targeted to maximise $P_{\mathrm{aCO}}$ reduction compared to conventional ventilator modes on long-term clinical outcomes (i.e. hyperinflation, exacerbations, cardiovascular complications, hospitalisations, survival, costs, patient adherence).

The role of adaptive/auto-titrating modes to improve the long-term outcome of COPD, acute exacerbation versus chronic stable hypercapnic COPD and optimisation of overnight ventilation, especially in specific subgroups in which ventilatory requirements may vary substantially overnight.

The assessment of auto-EPAP modes (in addition to adaptive/auto-titrating modes) in the sub-group of patients with COPD-OSA overlap syndrome.

The clinical efficacy and cost effectiveness of auto-titrating modes in the inpatient versus outpatient settings avoiding the need for hospitalisation to initiate NIV, thereby increasing access to NIV.

PICO: target population-intervention-comparator-outcome; LTH-NIV: long-term home non-invasive ventilation; NIV: non-invasive ventilation; $P_{\mathrm{aCO}}$ : partial pressure of carbon dioxide in arterial blood; HRQL: health-related quality of life; OSA: obstructive sleep apnoea; EPAP: expiratory positive airway pressure.

about compliance, pattern of usage, respiratory rate, percentage of patient triggered breaths, leakage and, in some models, "breath to breath" display of pressure and flow time waveforms. Changes in some of the recorded parameters (e.g. respiratory rate and patient triggered breaths) in the preceding days have been able to predict exacerbations in COPD patients receiving LTH-NIV [124]. In addition, some manufacturers have developed algorithms for automatic estimation of leaks and residual upper airway obstructions (UAO). Residual UAO is common in patients undergoing nocturnal NIV [125] and their lack of correction has been associated with increased mortality in amyotrophic lateral sclerosis patients [126]. UAO estimation by algorithms showed reasonable accuracy compared with polysomnography and manual scoring [127]. For the near future, technical advances in these devices would allow their integration in telemedicine programmes, although specific studies in COPD home ventilated patients are lacking. Interestingly, telemonitoring added to standard care did not alter time to next acute hospital admission, increase hospital admissions and home visits overall, and did not improve HRQL in a cohort of patients with CRF in a randomised crossover trial [128]. 
Finally, patient-ventilator asynchrony (PVA) may occur during the night. Theoretically, these events can compromise the effectiveness of the ventilation, but their importance remains unknown, mainly for two reasons: the absence of validated guidelines containing the classification of PVA and the scoring procedure in home mechanically ventilated patients, and the limited number of studies addressing this issue, with conflicting results. In a small cohort of COPD patients receiving NIV at home, the adjustments directed towards the decrease in PVA improved morning breathlessness [129]. However, in another study, PVA has been demonstrated to have no impact on overnight gas exchange during set-up of LTH-NIV [130].

In summary, monitoring of COPD patients on LTH-NIV is focused on the control of nocturnal hypoventilation with overnight carbon dioxide monitoring. Further research on patient ventilator interactions is needed.

\section{Conclusion}

The task force developed actionable recommendations for four PICO questions, and narrative summaries for two other questions. These recommendations are accompanied by discussions of implementation considerations and suggestions for future research (table 3).

This clinical practice guideline was produced using comprehensive GRADE methodology. Each PICO question was informed by a comprehensive systematic review and certainty of evidence evaluated in order to guide discussion. Recommendation generation was performed using the Evidence-to-Decision process to ensure all relevant considerations were incorporated. One limitation in this guideline is the lack of patient input for PICO questions and outcome prioritisation. Despite this, the task force panel specifically tried to focus and prioritise patient-centred outcomes from available literature data, such as dyspnoea, quality of sleep and HRQL, and use these outcomes to drive recommendation generation. Given the limitations of the evidence, decisions about implementing LTH-NIV in COPD for many patients will depend upon resource constraints: whether NIV is funded by insurers, whether acclimation takes place in hospital or a sleep lab, etc. The feasibility of these recommendations may thus vary across health systems.

Our recommendations, based on the best available evidence, can guide the management of chronic hypercapnic respiratory failure in COPD patients aimed at improving patient outcomes. However, they should be interpreted as conditional recommendations and should be implemented based on patient-related factors, including individual values and preferences. Adequately designed and executed RCTs that properly measure and report all patient-important outcomes are still needed. We anticipate significant progress in the field of LTH-NIV in the forthcoming years and, as such, these recommendations will require re-evaluation in the future.

Conflict of interest: B. Ergan reports personal fees for advisory board work from Breas, outside the submitted work. S. Oczkowski has nothing to disclose. B. Rochwerg has nothing to disclose. A. Carlucci reports personal fees for consultancy from Resmed and Breas, personal fees for lectures from Philips, outside the submitted work. M. Chatwin has received lecturing fees on the subject of cough augmentation from Breas Medical, MPR and Phillips, is a member of Breas clinical advisory board, and has attended a tele-monitoring development meeting with Resmed. E. Clini has nothing to disclose. M. Elliott reports personal fees from Philips-Respironics, ResMed, and Fisher and Paykel, outside the submitted work. J. Gonzalez-Bermejo has nothing to disclose. N. Hart reports unrestricted grants from Fisher Paykel, Philips and Resmed within and outside the direct area of work commented on here with the funds held and managed by Guy's and St Thomas' NHS Foundation Trust; financial support from Philips for development of the MYOTRACE technology that has patent filed in Europe (US patent pending) outside the area of work commented on here; personal fees for lecturing from Philips-Respironics, Philips, Resmed, Fisher-Paykel both within and outside the area of work commented on here with funds held by Guy's and St Thomas' Charity; membership of the Pulmonary Research Advisory Board for Philips outside the area of work commented on here with the funds for this role held by Guy's and St Thomas' NHS Foundation Trust; and is Joint Editor-in-Chief for Thorax. M. Luján reports to be member of the Clinical Advisory Board from Breas and received speaking fees from ResMed and Philips, during the conduct of the study. J. Nasilowski reports personal fees for lectures from ResMed and Phillips, and employed consultancy from AirLiquide, outside the submitted work S. Nava reports personal fees for advisory board work from Breas and Philips, grants from Fisher and Paykel, outside the submitted work. J.L. Pépin reports grants from Air Liquide Foundation, Mutualia and Vitalaire, grants and personal fees from Agiradom, AstraZeneca, Philips and Resmed, personal fees from Boehringer Ingelheim, Jazz Pharmaceutical, Night Balance and SEFAM, outside the submitted work. L. Pisani reports personal fees and travel expense reimbursement from Resmed, travel expense reimbursement from Fisher and Paykel, personal fees from Chiesi and Menarini, outside the submitted work J.H. Storre reports grants and personal fees for lectures from Heinen und Löwenstein and VitalAire, grants, personal fees for lectures and non-financial support for meeting attendance from Vivisol $\mathrm{GmbH}$, grants from Weinmann Deutschland, personal fees for consultancy/advisory board work from Breas Medical, during the conduct of the study; personal fees for consultancy and lectures, and non-financial support for meeting attendance from Boehringer Ingelheim Pharma, personal fees for consultancy and lectures from SenTec AG, Keller Medical GmbH, Linde Deutschland and Santis GmbH, outside the submitted work. P. Wijkstra reports grants and personal fees from Philips, Resmed, grants from Vital Air, Vivisol and Goedegebuure, personal fees from Synapse and Bresotec, outside the submitted work. T. Tonia acts as ERS methodologist. J. Boyd is an employee of the European Lung Foundation. R. Scala has nothing to disclose. W. Windisch reports grants from Weinmann/Germany, Vivisol/Germany, Heinen und Löwenstein/Germany, VitalAire/Germany and Philips/Respironics/ 
USA, during the conduct of the study; lecture fees from companies dealing with mechanical ventilation (Weinmann/ Germany, Vivisol/Germany, Heinen und Löwenstein/Germany, VitalAire/Germany and Philips/Respironics/USA), outside the submitted work.

Support statement: This work was funded by the European Respiratory Society (grant: 2017-01). Funding information for this article has been deposited with the Crossref Funder Registry.

\section{References}

1 Windisch W, Geiseler J, Simon K, et al. German national guideline for treating chronic respiratory failure with invasive and non-invasive ventilation: revised edition 2017-part 1. Respiration 2018; 96: 66-97.

2 Windisch W, Geiseler J, Simon K, et al. German national guideline for treating chronic respiratory failure with invasive and non-invasive ventilation-revised edition 2017: part 2. Respiration 2018; 96: 171-203.

3 Rochwerg B, Brochard L, Elliott MW, et al. Official ERS/ATS clinical practice guidelines: noninvasive ventilaiton for acute respiratory failure. Eur Respir J 2017; 50: 1602426.

4 Schwarz SB, Magnet FS, Windisch W. Why high-intensity NPPV is favourable to low-intensity NPPV: clinical and physiological reasons. COPD 2017; 14: 389-395.

5 Masefield S, Vitacca M, Dreher M, et al. Attitudes and preferences of home mechanical ventilation users from four European countries: an ERS/ELF survey. ERJ Open Res 2017; 3: 00015-2017.

6 Guyatt GH, Oxman AD, Kunz R, et al. GRADE guidelines: 2. Framing the question and deciding on important outcomes. J Clin Epidemiol 2011; 64: 395-400.

7 Struik FM, Lacasse Y, Goldstein RS, et al. Nocturnal noninvasive positive pressure ventilation in stable COPD: a systematic review and individual patient data meta-analysis. Respir Med 2014; 108: 329-337.

8 Shen G, Shen X, Shen J, et al. Effects of long-term non-invasive ventilation in stable chronic obstructive pulmonary disease: a systematic review of 16 randomized controlled trials. Int J Clin Exp Med 2016; 9: 468-484.

9 Dretzke J, Moore D, Dave C, et al. The effect of domiciliary noninvasive ventilation on clinical outcomes in stable and recently hospitalized patients with COPD: a systematic review and meta-analysis. Int J Chron Obstruct Pulmon Dis 2016; 11: 2269.

10 Guyatt GH, Oxman AD, Vist G, et al. GRADE guidelines: 4. Rating the quality of evidence-study limitations (risk of bias). J Clin Epidemiol 2011; 64: 407-415.

11 Guyatt GH, Oxman AD, Kunz R, et al. GRADE guidelines: 7. Rating the quality of evidence-inconsistency. J Clin Epidemiol 2011; 64: 1294-1302.

12 Guyatt GH, Oxman AD, Kunz R, et al. GRADE guidelines: 8. Rating the quality of evidence-indirectness. J Clin Epidemiol 2011; 64: 1303-1310.

13 Guyatt GH, Oxman AD, Kunz R, et al. GRADE guidelines 6. Rating the quality of evidence-imprecision. J Clin Epidemiol 2011; 64: 1283-1293.

14 GRADE Working Group. Guideline Development Tool. 2014. https://gdt.gradepro.org/app/handbook/handbook. html Date last accessed: September 20, 2018.

15 Alonso-Coello P, Oxman AD, Moberg J, et al. GRADE Evidence to Decision (EtD) frameworks: a systematic and transparent approach to making well informed healthcare choices. 2: Clinical practice guidelines. BMJ 2016; 353: i2089.

16 Andrews JC, Schunemann HJ, Oxman AD, et al. GRADE guidelines: 15. Going from evidence to recommendation - determinants of a recommendation's direction and strength. J Clin Epidemiol 2013; 66: 726-735.

17 Guyatt GH, Oxman AD, Kunz R, et al. Going from evidence to recommendations. BMJ 2008; 336: 1049-1051.

18 Rochwerg B, Alhazzani W, Jaeschke R. Clinical meaning of the GRADE rules. Intensive Care Med 2014; 40: 877-879.

19 Ambrosino N, Simonds A. The clinical management in extremely severe COPD. Respir Med 2007; 101: $1613-1624$.

20 Chapman KR, Mannino DM, Soriano JB, et al. Epidemiology and costs of chronic obstructive pulmonary disease. Eur Respir J 2006; 27: 188-207.

21 Ahmadi Z, Bornefalk-Hermansson A, Franklin KA, et al. Hypo-and hypercapnia predict mortality in oxygen-dependent chronic obstructive pulmonary disease: a population-based prospective study. Respir Res 2014; 15: 30 .

22 Saraiva C, Abreu T, Neves D, et al. Mortality predictive factors in subjects with COPD after a pulmonary rehabilitation program: a 3-year study. Respir Care 2016; 61: 1179-1185.

23 Connors AF Jr, Dawson NV, Thomas C, et al. Outcomes following acute exacerbation of severe chronic obstructive lung disease. The SUPPORT Investigators (Study to understand prognoses and preferences for outcomes and risks of treatments). Am J Respir Crit Care Med 1996; 154: 959-967.

24 Costello R, Deegan P, Fitzpatrick M, et al. Reversible hypercapnia in chronic obstructive pulmonary disease: a distinct pattern of respiratory failure with a favorable prognosis. Am J Med 1997; 102: 239-244.

25 Foucher P, Baudouin N, Merati M, et al. Relative survival analysis of 252 patients with COPD receiving long-term oxygen therapy. Chest 1998; 113: 1580-1587.

26 Windisch W, Storre JH, Köhnlein T. Nocturnal non-invasive positive pressure ventilation for COPD. Expert Rev Respir Med 2015; 9: 295-308.

27 Crimi C, Noto A, Princi P, et al. Domiciliary non-invasive ventilation in COPD: an international survey of indications and practices. COPD 2016; 13: 483-490.

28 Nava S, Fanfulla F, Frigerio P, et al. Physiologic evaluation of 4 weeks of nocturnal nasal positive pressure ventilation in stable hypercapnic patients with chronic obstructive pulmonary disease. Respiration 2001; 68: 573-583.

29 Turkington PM, Elliott MW. Rationale for the use of non-invasive ventilation in chronic ventilatory failure. Thorax 2000; 55: 417-423.

30 Windisch W, Dreher M, Storre JH, et al. Nocturnal non-invasive positive pressure ventilation: physiological effects on spontaneous breathing. Respir Physiol Neurobiol 2006; 150: 251-260. 
McEvoy RD, Pierce RJ, Hillman D, et al. Nocturnal non-invasive nasal ventilation in stable hypercapnic COPD: a randomised controlled trial. Thorax 2009; 64: 561-566.

32 Windisch W, Vogel M, Sorichter S, et al. Normocapnia during nIPPV in chronic hypercapnic COPD reduces subsequent spontaneous $\mathrm{PaCO}_{2}$. Respir Med 2002; 96: 572-579.

33 Windisch W, Kostić S, Dreher M, et al. Outcome of patients with stable COPD receiving controlled noninvasive positive pressure ventilation aimed at a maximal reduction of $\mathrm{Pa}\left(\mathrm{CO}_{2}\right)$. Chest 2005; 128: 657-662.

34 Dreher M, Storre JH, Schmoor C, et al. High-intensity versus low-intensity non-invasive ventilation in patients with stable hypercapnic COPD: a randomised crossover trial. Thorax 2010; 65: 303-308.

35 Windisch W, Haenel $\mathrm{M}$, Storre $\mathrm{JH}$, et al. High-intensity non-invasive positive pressure ventilation for stable hypercapnic COPD. Int J Med Sci 2009; 6: 72-76.

36 Köhnlein T, Windisch W, Köhler D, et al. Non-invasive positive pressure ventilation for the treatment of severe stable chronic obstructive pulmonary disease: a prospective, multicentre, randomised, controlled clinical trial. Lancet Respir Med 2014; 2: 698-705.

37 Hoogendoorn M, Hoogenveen RT, Rutten-van Mölken MP, et al. Case fatality of COPD exacerbations: a meta-analysis and statistical modelling approach. Eur Respir J 2011; 37: 508-515.

38 Clini E, Sturani C, Rossi A, et al. The Italian multicentre study on noninvasive ventilation in chronic obstructive pulmonary disease patients. Eur Respir J 2002; 20: 529-538.

39 Duiverman ML, Wempe JB, Bladder G, et al. Nocturnal non-invasive ventilation in addition to rehabilitation in hypercapnic patients with COPD. Thorax 2008; 63: 1052-1057.

40 Strumpf DA, Millman RP, Carlisle CC, et al. Nocturnal positive -pressure ventilation via nasal mask in patients with severe chronic obstructive pulmonary disease. Am Rev Respir Dis 1991; 144: 1234-1239.

41 Gay PC, Hubmayr RD, Stroetz RW. Efficacy of nocturnal nasal ventilation in stable, severe chronic obstructive pulmonary disease during a 3-month controlled trial. Mayo Clin Proc 1996; 71: 533-542.

42 Kaminski D, Sliwinski P, Bielen P, et al. Noninvasive positive pressure ventilation in COPD patients with hypercapnic respiratory failure. Pneumonol Alergol Pol 1999; 67: 45-52.

43 Garrod R, Mikelsons C, Paul EA, et al. Randomized controlled trial of domiciliary noninvasive positive pressure ventilation and physical training in severe chronic obstructive pulmonary disease. Am J Respir Crit Care Med 2000; 162: 1335-1341.

44 Casanova C, Celli BR, Tost L, et al. Long-term controlled trial of nocturnal nasal positive pressure ventilation in patients with severe COPD. Chest 2000; 118: 1582-1590.

45 Sin DD, Wong E, Mayers I, et al. Effects of nocturnal noninvasive mechanical ventilation on heart rate variability of patients with advanced COPD. Chest 2007; 131: 156-163.

46 Bhatt SP, Peterson MW, Wilson JS, et al. Noninvasive positive pressure ventilation in subjects with stable COPD: a randomized trial. Int J Chron Obstruct Pulmon Dis 2013; 8: 581-589.

47 Shebl RE, Abderaboh MM. Bi-level positive airway pressure ventilation for patients with stable chronic obstructive pulmonary disease. Egypt J Chest Dis Tuberc 2015; 64: 395-398.

48 Zhou L, Li X, Guan L, et al. Home noninvasive positive pressure ventilation with built in software in stable hypercapnic COPD: a short-term prospective, multicenter, randomized, controlled trial. Int J Chron Obstruct Pulmon Dis 2017; 12: 1279-1286.

49 Chiang LL, Liu CY, Ho SC, et al. Efficacy of nocturnal nasal positive pressure ventilation in hypercapnic patients with severe obstructive lung diseases. Chang Gung Med J 2004; 27: 98-106.

50 Marquez-Martin E, Ruiz FO, Ramos PC, et al. Randomized trial of non-invasive ventilation combined with exercise training in patients with chronic hypercapnic failure due to chronic obstructive pulmonary disease. Respir Med 2014; 108: 1741-1751.

51 Schneeberger T, Stegemann A, Schoenheit-Kenn U, et al. Nocturnal non invasive ventilation as an adjunct for pulmonary rehabilitation in patients with very severe COPS- a randomized controlled trial. Am J Respir Crit Care Med 2017; 195: A2851.

52 Jones PW, Beeh KM, Chapman KR, et al. Minimal clinically important differences in pharmacological trials. Am J Respir Crit Care Med 2014; 189: 250-255.

53 Nava S, Navalesi P, Gregoretti C. Interfaces and humidification for noninvasive mechanical ventilation. Respir Care 2009; 54: 71-84.

54 Brill AK. How to avoid interface problems in acute noninvasive ventilation. Breathe 2014; 10: $230-242$.

55 Tuggey JM, Plant PK, Elliott MW. Domiciliary non-invasive ventilation for recurrent acidotic exacerbations of COPD: an economic analysis. Thorax 2003; 58: 867-871.

56 Lujan M, Lalmolda C, Ergan B. Basic concepts for tidal volume and leakage estimation in non-invasive ventilation. Turk Thorac J 2019; 20: 140-144.

57 Skoczyński S, Scala R, Navalesi P. Survey on accessibility and real-life application of noninvasive ventilation. ERJ Open Res 2018; 4: 00062-2018.

58 Lun CT, Tsui MS, Cheng SL, et al. Differences in baseline factors and survival between normocapnia, compensated respiratory acidosis and decompensated respiratory acidosis in COPD exacerbation: a pilot study. Respirology 2016; 21: 128-136.

59 Xiang PC, Zhang X, Yang JN, et al. [The efficacy and safety of long term home noninvasive positive pressure ventilation in patients with stable severe chronic obstructive pulmonary disease]. Zhonghua Jie $\mathrm{He} \mathrm{He} \mathrm{Hu} \mathrm{Xi} \mathrm{Za}$ Zhi 2007; 30: 746-750.

60 Cheung AP, Chan VL, Liong JT, et al. A pilot trial of non-invasive home ventilation after acidotic respiratory failure in chronic obstructive pulmonary disease. Int J Tuberc Lung Dis 2010; 14: 642-649.

61 Struik FM, Sprooten RT, Kerstjens HA, et al. Nocturnal non-invasive ventilation in COPD patients with prolonged hypercapnia after ventilatory support for acute respiratory failure: a randomised, controlled, parallel-group study. Thorax 2014; 69: 826-834.

62 Murphy PB, Rehal S, Arbane G, et al. Effect of home noninvasive ventilation with oxygen therapy vs oxygen therapy alone on hospital readmission or death after an acute COPD exacerbation: a randomized clinical trial. JAMA 2017; 317: 2177-2186.

63 Funk GC, Breyer MK, Burghuber OC, et al. Long-term non-invasive ventilation in COPD after acute-on-chronic respiratory failure. Respir Med 2011; 105: 427-434. 
64 Lukácsovits J, Carlucci A, Hill N, et al. Physiological changes during low- and high-intensity noninvasive ventilation. Eur Respir J 2012; 39: 869-875.

65 Duiverman ML, Maagh P, Magnet FS, et al. Impact of High-Intensity-NIV on the heart in stable COPD: a randomised cross-over pilot study. Respir Res 2017; 18: 76.

66 Dreher M, Ekkernkamp E, Walterspacher S, et al. Noninvasive ventilation in COPD: impact of inspiratory pressure levels on sleep quality. Chest 2011; 140: 939-945.

67 Murphy PB, Brignall K, Moxham J, et al. High pressure versus high intensity noninvasive ventilation in stable hypercapnic chronic obstructive pulmonary disease: a randomized crossover trial. Int J Chron Obstruct Pulmon Dis 2012; 7: 811-818.

68 Windisch W, Storre JH, Sorichter S, et al. Comparison of volume- and pressure-limited NPPV at night: a prospective randomized cross-over trial. Respir Med 2005; 99: 52-59.

69 Tuggey JM, Elliott MW. Randomised crossover study of pressure and volume non-invasive ventilation in chest wall deformity. Thorax 2005; 60: 859-864.

70 Mehta S, McCool FD, Hill NS. Leak compensation in positive pressure ventilators: a lung model study. Eur Respir J 2001; 17: 259-267.

71 Meecham Jones DJ, Wedzicha JA. Comparison of pressure and volume preset nasal ventilator systems in stable chronic respiratory failure. Eur Respir J 1993; 6: 1060-1064.

72 Elliott MW, Aquilina R, Green M, et al. A comparison of different modes of noninvasive ventilatory support: effects on ventilation and inspiratory muscle effort. Anaesthesia 1994; 49: 279-283.

73 Schönhofer B, Sonneborn M, Haidl P, et al. Comparison of two different modes for noninvasive mechanical ventilation in chronic respiratory failure: volume versus pressure controlled device. Eur Respir J 1997; 10: 184-191.

74 Smith IE, Shneerson JM. Secondary failure of nasal intermittent positive pressure ventilation using the Monnal D: effects of changing ventilator. Thorax 1997; 52: 89.

75 Storre JH, Bohm P, Dreher M, et al. Clinical impact of leak compensation during non-invasive ventilation. Respir Med 2009; 103: 1477-1483.

76 Arellano-Maric MP, Gregoretti C, Duivermann M, et al. Long-term volume-targeted pressure-controlled ventilation: sense or nonsense? Eur Respir J 2017; 49: 1602193.

77 Crisafulli E, Manni G, Kidonias M, et al. Subjective sleep quality during average volume assured pressure support (AVAPS) ventilation in patients with hypercapnic COPD: a physiological pilot study. Lung 2009; 187: 299-305.

78 Oscroft NS, Ali M, Gulati A, et al. A randomised crossover trial comparing volume assured and pressure preset noninvasive ventilation in stable hypercapnic COPD. COPD 2010; 7: 398-403.

79 Oscroft NS, Chadwick R, Davies MG, et al. Volume assured versus pressure preset non-invasive ventilation for compensated ventilatory failure in COPD. Respir Med 2014; 108: 1508-1515.

80 Storre JH, Matrosovich E, Ekkernkamp E, et al. Home mechanical ventilation for COPD: high-intensity versus target volume noninvasive ventilation. Respir Care 2014; 59: 1389-1397.

81 Ekkernkamp E, Storre JH, Windisch W, et al. Impact of intelligent volume-assured pressure support on sleep quality in stable hypercapnic chronic obstructive pulmonary disease patients: a randomized, crossover study. Respiration 2014; 88: 270-276.

82 Nilius G, Katamadze N, Domanski U, et al. Non-invasive ventilation with intelligent volume-assured pressure support versus pressure-controlled ventilation: effects on the respiratory event rate and sleep quality in COPD with chronic hypercapnia. Int J Chron Obstruct Pulmon Dis 2017; 12: 1039-1045.

83 Borel JC, Pepin JL, Pison C, et al. Long-term adherence with non-invasive ventilation improves prognosis in obese COPD patients. Respirology 2014; 19: 857-865.

84 Dudgeon D, Baracos VE. Physiological and functional failure in chronic obstructive pulmonary disease, congestive heart failure and cancer: a debilitating intersection of sarcopenia, cachexia and breathlessness. Curr Opin Support Palliat Care 2016; 10: 236-241.

85 Budweiser S, Heinemann F, Meyer K, et al. Weight gain in cachectic COPD patients receiving non-invasive positive pressure ventilation. Respir Care 2006; 51: 126-132.

86 Garcia-Aymerich J, Gómez FP, Benet M, et al. Identification and prospective validation of clinically relevant chronic obstructive pulmonary disease (COPD) subtypes. Thorax 2011; 66: 430-437.

87 Arnal JM, Texereau J, Garnero A. Practical insight to monitor home NIV in COPD patients. COPD 2017; 14: 401-410.

88 Navalesi P, Fanfulla F, Frigerio P, et al. Physiologic evaluation of noninvasive mechancial ventilation delivered with the three types of masks in patients with chronic hypercapnic respiratory failure. Crit Care Med 2000; 28: $1785-1790$.

89 Callegari J, Magnet FS, Taubner S, et al. Interfaces and ventilator settings for long-term noninvasive ventilation in COPD patients. Int J Chron Obstruct Pulmon Dis 2017; 12: 1883-1889.

90 Storre JH, Huttmann SE, Ekkernkamp E, et al. Oxygen supplementation in noninvasive home mechanical ventilation: the crucial roles of $\mathrm{CO}_{2}$ exhalation systems and leakages. Respir Care 2014; 59: 113-120.

91 American Association for Respiratory Care, Restrepo RD, Walsh BK. Humidification during invasive and noninvasive mechanical ventilation. Respir Care 2012; 57: 782-788.

92 Lellouche F, Maggiore SM, Deye N, et al. Effect of the humidification device on the work of breathing during noninvasive ventilation. Intensive Care Med 2002; 28: 1582-1589.

93 Hardinge M, Annandane J, Bourne S, et al. British Thoracic Society guidelines for home oxygen use in adults. Thorax 2015; 70: Suppl. 1, i1-i43.

94 Spruit MA, Singh SJ, Garvey C, et al. An official American Thoracic Society/European Respiratory Society statement: key concepts and advances in pulmonary rehabilitation. Am J Respir Crit Care Med 2013; 188: e13-e64.

95 McCarthy B, Casey D, Devane D, et al. Pulmonary rehabilitation for chronic obstructive pulmonary disease. Cochrane Database Syst Rev 2015: CD003793.

96 Puhan MA, Gimeno-Sants E, Cates CJ, et al. Pulmonary rehabilitation following exacerbations of chronic obstructive pulmonary disease. Cochrane Database Syst Rev 2016; 12: CD005305. 
Vitacca M, Kaymaz D, Lanini B, et al. Non-invasive ventilation during cycle exercise training in patients with chronic respiratory failure on long-term ventilatory support: a randomized controlled trial. Respirology 2018; 23: $182-189$.

98 Costes F, Agresti A, Court-Fortune I, et al. Noninvasive ventilation during exercise training improves exercise tolerance in patients with chronic obstructive pulmonary disease. J Cardiopulm Rehabil 2003; 23: 307-313.

99 Keilty SE, Ponte J, Fleming TA, et al. Effect of inspiratory pressure support on exercise tolerance and breathlessness in patients with severe stable chronic obstructive pulmonary disease. Thorax 1994; 49: 990-994.

100 Hawkins P, Johnson LC, Nikoletou D, et al. Proportional assist ventilation as an aid to exercise training in severe chronic obstructive pulmonary disease. Thorax 2002; 57: 853-859.

101 Dreher M, Storre JH, Windisch W. Noninvasive ventilation during walking in patients with severe COPD: a randomised cross-over trial. Eur Respir J 2007; 29: 930-936.

102 Menadue C, Piper AJ, vant Hul AJ, et al. Non-invasive ventilation during exercise training for people with chronic obstructive pulmonary disease. Cochrane Database Syst Rev 2014: CD007714.

103 Ricci C, Terzoni S, Gaeta $M$, et al. Physical training and noninvasive ventilation in COPD patients: a meta-analysis. Respir Care 2014; 59: 709-717.

104 Camillo CA, Osadnik CR, van Remoortel H, et al. Effect of "add-on" interventions on exercise training in individuals with COPD: a systematic review. ERJ Open Res 2016; 2: 00078-2015.

105 Bolton CE, Bevan-Smith EF, Blakey JD, et al. British Thoracic Society guideline on pulmonary rehabilitation in adults. Thorax 2013; 68: Suppl. 2, iil-ii30.

106 Duiverman ML, Wempe JB, Bladder G, et al. Two-year home-based nocturnal noninvasive ventilation added to rehabilitation in chronic obstructive pulmonary disease patients: a randomized controlled trial. Respir Res 2011; 12: 112 .

107 Coquart JB, Le Rouzic O, Racil G, et al. Real-life feasibility and effectiveness of home-based pulmonary rehabilitation in chronic obstructive pulmonary disease requiring medical equipment. Int J Chron Obstruct Pulmon Dis 2017; 12: 3549-3556.

108 Osadnik CR, McDonald CF, Jones AP, et al. Airway clearance techniques for chronic obstructive pulmonary disease. Cochrane Database Syst Rev 2012: CD008328.

109 Burudpakdee C, Seetasith A, Kauffman G, et al. A real-world study of 30-day exacerbation outcomes in chronic obstructive pulmonary disease (COPD) patients managed with Aerobika OPEP. Pulmonary Therapy 2017; 3 : 163-171.

110 Winck JC, Gonçalves MR, Lourenco C, et al. Effects of mechanical insufflation-exsufflation on respiratory parameters for patients with chronic airway secretion encumbrance. Chest 2004; 126: 774-780.

111 Poole P, Chong J, Cates CJ. Mucolytic agents versus placebo for chronic bronchitis or chronic obstructive pulmonary disease. Cochrane Database Syst Rev 2015: CD001287.

112 Cazzola M, Rogliani P, Calzetta L, et al. Impact of mucolytic agents on COPD exacerbations: a pair-wise and network meta-analysis. COPD 2017; 14: 552-563.

113 Wedzicha JA, Calverley PMA, Albert RK, et al. Prevention of COPD exacerbations: a European Respiratory Society/American Thoracic Society guideline. Eur Respir J 2017; 50: 1602265.

114 Patout M, Arbane G, Cuvelier A, et al. Polysomnography versus limited respiratory monitoring and nurse-led titration to optimise non-invasive ventilation set-up: a pilot randomised clinical trial. Thorax 2019; 74: 83-86.

115 Berry RB, Budhiraja R, Gottlieb DJ, et al. Rules for scoring respiratory events in sleep: update of the 2007 AASM manual for the scoring of sleep and associated events. Deliberations of the Sleep Apnea Definitions Task Force of the American Academy of Sleep Medicine. J Clin Sleep Med 2012; 8: 597-619.

116 Schwarz SB, Callegari J, Hamm C, et al. Is outpatient control of long-term non-invasive ventilation feasible in chronic obstructive pulmonary disease patients? Respiration 2018; 95: 154-160.

117 Storre JH, Magnet FS, Dreher M, et al. Transcutaneous monitoring as a replacement for arterial $\mathrm{PCO}_{2}$ monitoring during nocturnal non-invasive ventilation. Respir Med 2011; 105: 143-150.

118 Storre JH, Steurer B, Kabitz HJ, et al. Transcutaneous $\mathrm{PCO}_{2}$ monitoring during initiation of noninvasive ventilation. Chest 2007; 132: 1810-1816.

119 Nardi J, Prigent H, Adala A, et al. Nocturnal oximetry and transcutaneous carbon dioxide in home ventilated neuromuscular patients. Respir Care 2012; 57: 1425-1430

120 Aarrestad S, Tollefsen E, Kleiven AL, et al. Validity of transcutaneous $\mathrm{PCO}_{2}$ in monitoring chronic hypoventilation treated with non-invasive ventilation. Respir Med 2016; 112: 112-118.

121 Kitajima T, Marumo S, Shima H, et al. Clinical impact of episodic nocturnal hypercapnia and its treatment with noninvasive positive pressure ventilation in patients with stable advanced COPD. Int J Chron Obstruct Pulmon Dis 2018; 13: 843-853.

122 Huttmann SE, Windisch W, Storre JH. Techniques for the measurement and monitoring of carbon dioxide in the blood. Ann Am Thor Soc 2014; 11: 645-652.

123 Schwarz SB, Windisch W, Magnet FS, et al. Continuous non-invasive $\mathrm{PCO}_{2}$ monitoring in weaning patients: transcutaneous is advantageous over end-tidal $\mathrm{PCO}_{2}$. Respirology 2017; 22: 1579-1584.

124 Borel JC, Pelletier J, Taleux N, et al. Parameters recorded by software of noninvasive ventilators predict COPD exacerbation: a proof-of-concept study. Thorax 2015; 70: 284-285.

125 Aarrestad S, Qvarfort M, Kleiven AL, et al. Sleep related respiratory events during non-invasive ventilation of patients with chronic hypoventilation. Respir Med 2017; 132: 210-216.

126 Georges M, Attali V, Golmard JL, et al. Reduced survival in patients with ALS with upper airway obstructive events on non-invasive ventilation. J Neurol Neurosurg Psychiatry 2016; 87: 1045-1050.

127 Georges M, Adler D, Contal O, et al. Reliability of apnea-hypopnea index measured by a home bi-level pressure support ventilator versus a polysomnographic assessment. Respir Care 2015; 60: 1051-1056.

128 Chatwin M, Hawkins G, Panicchia L, et al. Randomized crossover trial of telemonitoring in chronic respiratory patients (TeleCRAFT trial). Thorax 2016; 71: 305-311.

129 Adler D, Perrig S, Takahashi H, et al. Polysomnography in stable COPD under non-invasive ventilation to reduce patient-ventilator asynchrony and morning breathlessness. Sleep Breath 2012; 16: 1081-1090.

130 Ramsay M, Mandal S, Suh ES, et al. Parasternal electromyography to determine the relationship between patient-ventilator asynchrony and nocturnal gas exchange during home mechanical ventilation set-up. Thorax 2015; 70: 946-952. 